\title{
sciendo
}

Research Article

(C) 2019 Potikruprasert et.al. This is an open access article licensed under the Creative Commons Attribution-NonCommercial-NoDerivs License (http://creativecommons.org/licenses/by-nc-nd/3.0/).

\section{A Confirmatory Factor Analysis Model of Academic Service-Learning Principles used in The Institute of Vocational Education in Thailand}

\author{
Chantana Potikruprasert \\ Ph.D. Candidate, Faculty of Industrial and Technology, \\ King Mongkut's Institute of Technology Ladkrabang, \\ Bangkok, Thailand

\section{Pariyaporn Tungkunanan}

Faculty of Industrial and Technology, King Mongkut's Institute of Technology Ladkrabang, Bangkok, Thailand

\section{Siripan Choomnoom}

Senior Advisor of Office of Vocational Education Commission, Bangkok, Thailand

Doi: $10.2478 / m j s s-2019-0034$

\section{Abstract}

The principle of service is at the heart of the academic service-learning of the Institute of Vocational Education, Bangkok, in Thailand. Therefore, the confirmatory factors of this academic service-learning were studied. The purpose of the research is to study the factors of academic service-learning principles. The results of the analysis of the confirmatory factors of the academic service-learning principles and the professions of the Institute of Vocational Education, Bangkok, were consistent with the empirical evidence. After the standard factors were considered, it was found that there were 5 confirmatory factors:; the principle of trustworthiness, the principle of confidence, the principle of instant response, the principle of regard, and the principle of objectiveness. The values of the factors were 0.84 , $0.92,0.90,0.92$, and 0.89, respectively. The statistical significance of all factors was .05

Keywords: Factor Analysis of Academic Service-Learning Principles, Academic Service-Learning Principles, Institute of Vocational Education, Bangkok

\section{Introduction}

The Internal and external changes can both have effects on the future development of Thailand. After many years of development, Thailand still has problems of economy structure, environment, and country management. Therefore, there must be a proper and sustainable development strategy in place in order to develop the country following the philosophy of sufficiency economy., The concept of holistically integrative development, that "human is development center.", that means humanity, society, the economy, the environment, and politics must be holistically integrated and developed. In addition, the development process must have the participation of all sections of society (Office of the National Economic and Social Development Board. 2013)

To develop the community to be strong, the government or other concerned parties have to seriously support community learning, because effective learning can guide people in solving 
problems in their daily lives and continuously develop the community. Moreover, local wisdom is supported and the resultant benefits extended. The new economic model is an important strategy under the lead of the prime minister and specifies "stability, wealth and durability" by encouraging "internal strength" and supporting "the people" to follow "the philosophy of sufficiency economy". Many countries have issued new economic models in order to make their countries wealthy in the 21st century. The United States of America has "A Nation of Makers", the UK support "Design in Innovation", China has announced "Made in China 2025", India is driving "Made in India", and South Korea has "Creative Economy". Thailand itself has instigated "Thailand 4.0", in which the concept of "Strength Form Within" consists of three elements:; 1) Innovation Driven Proposition, 2) Entrepreneur Driven Proposition, and 3) Community Driven Proposition.

Mesinsi (2016) stated that the principle of community development needed a systematic approach, due to the fact that community development is not sustainable. The community is being changed all the time. Therefore, the community must be developed by use of a continuous learning process. There are many processes used by schools to develop the community, such as academic service-learning, making community leaders, developing learning processes, and community learning management (Thamkittipob. 2010) related with Kathleen B. Wasserman, (2010) stated many universities around the world are using service learning in courses to enhance their students' mastery of course content and commitment to social justice. Teacher education faculties have additionally experimented with service learning as a way of providing authentic field experiences at inner city schools for their teacher candidates.

The policy of the Institute of Vocational Education, Bangkok focuses on academic servicelearning, which is featured in the Vocational Education Act B.E. 2551. However, the form and the process of the academic service-learning principles of the Institute of Vocational Education, Bangkok have not been clarified. Therefore, it would be interesting to study the form of academic service-learning principles of this institute, which is under the Office of the Vocational Education Commission, in order for them to be guidelines for academic service-learning management for communities and for effective development of life quality in those communities.

\section{Problem of Research}

The academic service is a mission of university as it stated in the third strategy that the academic service-learning and lifelong learning can support good relationship and useful for the society. It is because learning from the research can be used to develop the community, then the society can be improved and be able to stay on their own. It can be seen that university spend a lot of money for the academic service because of its importance. This is also consistent with the strategy policy and the demand of the community. (Office of the Vocational Education Commission, 2014).

\section{Objective}

To perform a factor analysis of academic service-learning principles used in the Institute of Vocational Education, Bangkok, in Thailand.

\section{Methodology of Research}

\subsection{General Background of Research}

Concepts of service principles as defined by organizations, academicians, and researchers were studied from 1) Wittaya Danthamrongkun (2004) 2) Jittinan Nantapaiboon(2008) 3) Pisit Pipatpokakun(2008) and 4) Berry, Zeithamal and Parasuraman(1990). The ideal as defined by organizations, academicians, and researchers were studied and then synthesized. It was concluded that there were 5 a factors of academic service learning principles in the Institute of Vocational Education, Bangkok, as follows:and then synthesized. It was concluded that there were 5 a factors of academic service learning principles in the Institute of Vocational Education, Bangkok, as follows: 
1. The principle of trustworthiness means the knowledge and ability of the academic and professional service providers to the recipient properly, Polite and friendly

2. The principle of confidence means the confidence in the academic and professional services that to provide the exact service with integrity which is respond to the needs.

3. The principle of instant response means the readiness of the potential personnel that response for the requirement of customers in a timely manner.

4. The principle of regard means being courteous, willing to pay attention to the needs of the academic and professional service providers with consistently, benefit of the recipient.

5. The principle of objectiveness means materiality, quality of service. There are location, equipment, materials and personnel, and enables the service provider to recognize that the service provider is willing to serve.

\subsection{Sample of Research}

\subsubsection{Population and Samples}

Population: The population used consisted of 65 directors of vocational training colleges in Bangkok, 110 teachers and 14 directors of the vocational education institutes, which fell under the Institute of Vocational Education, Bangkok, and 250 representatives of enterprises, which cooperate with undergraduate education management. There was a population of, in total 449.

Samples: The samples used consisted of 55 directors of vocational training colleges in Bangkok, 90 teachers and 9 directors of vocational education institutes, which fell under the institute of Vocational Education, Bangkok, and 230 representatives of enterprises, which cooperate with undergraduate education management; in total, 384 samples. The concept of confirmatory factor analysis was used to specify the size of the samples. The basic rule is that a sample from .35 should be used from 350 samples or more follow on theory of Hair [11], and that stratified random-sampling is used.

\subsubsection{Variables}

There were 5 main factors of service principles, as follows:

1. The principle of trustworthiness;

2. The principle of confidence;

3. The principle of instant response;

4. The principle of regard, and

5. The principle of objectiveness

\subsubsection{Instrument and Procedures}

Research Instrument was the questionnaire with 5 rating scale, which there were 3 processes:

1. After the concepts, theories, researches, and relevant documentation of the academic service-learning principles of the Institute of Vocational Education, Bangkok, were studied, a questionnaire was used as a tool. This was divided into two parts, as follows.

Part 1 was a check list of general information about the informant.

Part 2 was a rating scale of five levels, used in order to ask for the confirmatory factors of the academic service-learning principles of the Institute of Vocational Education, Bangkok; this consisted of the principles of trustworthiness, confidence, instant response, regard, and objectiveness.

The criteria of the score was as below:

$\begin{array}{lll}\text { Score } & \text { means } & \text { Level of comment } \\ 5 & \text { definitely agree } \\ 4 & \text { means } & \text { agree strongly } \\ 3 & \text { means } & \text { partly agree } \\ 2 & \text { means } & \text { lightly agree } \\ 1 & \text { means } & \text { rarely agree }\end{array}$


2. To ascertain the quality of the research tool, the questionnaire was sent to five experts in order to check content validity and then analyze and find the consistency index value (IOC). The IOC between the questionnaire and the definitions should not have been lower than .50 , which means a questionnaire is consistent with the definitions. The IOC in this research was $.060-1.00$.

3. The questionnaire was improved and corrected as per the advice of the experts. Then, the questionnaire was tested by 30 people: directors of the Institute of Vocational Education, Bangkok; teachers and, directors of vocational training colleges, which fall under the Institute of Vocational Education, Bangkok; , and representatives of enterprises, which cooperate with undergraduate education management. After that, the reliability of the questionnaire was calculated by the way of Cronbach's Alpha (1951) the reliability ascertained was .934 .

\section{Data Collection}

The confirmatory factors of the academic service-learning principles of the Institute of Vocational Education, Bangkok, were sent to the directors of that institute and the directors of vocational training colleges in Bangkok by post and hand delivery. There are 368 replied questionnaires or $95.83 \%$.

\section{Data Analysis}

The steps of confirmatory factor analysis of the academic service-learning principles of the Institute of Vocational Education, Bangkok, were as follows:.

1. The general information of the informant was analyzed by frequency value and percentage.

2. The level of comment on service principle was analyzed by mean and standard deviation.

3. Confirmatory Factor Analysis: CFA was used to analyze the service principles of the Institute of Vocational Education, Bangkok.

\section{Results of Research}

\subsection{Results of general information}

Table 1: Quantities and percentages of general information

\begin{tabular}{llcc}
\hline Variables & General Status & Quantity & Percentage \\
\hline & Director of the Institute of Vocational Education, Bangkok & 11 & 2.99 \\
Position in the & Director of vocational training college in Bangkok & 50 & 13.59 \\
present & Teacher & 83 & 22.55 \\
& Representative of enterprises, which cooperate with undergraduate & 224 & 60.87 \\
& education management & 368 & 100.00 \\
& Total & 74 & 20.11 \\
& Minburi Technical College & 22 & 5.98 \\
& Kanchanapisek Technical College Mahanakorn & 6 & 1.63 \\
Vocational training & Donmueang Technical College & 29 & 7.88 \\
colleges, which & Dusit Technical College & 40 & 10.87 \\
participates in & Rajasittharam Technical College & 13 & 3.53 \\
academic service- & Saowabha Vocational College & 8 & 2.17 \\
learning & Thon Buri Vocational Education College & 28 & 7.61 \\
& Bnthrachai Commercial College & 7 & 1.90 \\
& Chetupon Commercial College & 28 & 10.33 \\
& Thon Buri Commercial College & 38 & 5.16 \\
& Golden Jubilee Goldsmith College & 19 & 4.35 \\
\hline & Kanchanapisek Vocational Training College & 16 & 18.48 \\
& Nong Chok & 68 & $\mathbf{1 0 0 . 0 0}$ \\
\hline
\end{tabular}


Table 1 showed that the largest group of informants comprised 224 representatives of enterprises, who cooperate with undergraduate education management, at $60.87 \%$. The second comprised 83 teachers, at $22.55 \%$, and the last comprised 11 directors of the Institute of Vocational Education, Bangkok, at $2.99 \%$

Most informants were from Minburi Technical College, with 74 people, or $20.11 \%$. The second were largest group of informants were from Kanchanapisek Vocational Training College, Nong Chok, with 68 people, or $18.48 \%$. The smallest group of informants comprised six, or $1.63 \%$, from Donmueang Technical College.

Table 2: Means and standard deviations of the academic service-learning principles and professions of the Institute of Vocational Education, Bangkok

\begin{tabular}{lccc}
\hline Variables & $\overline{\mathbf{X}}$ & S.D. & Meaning \\
\hline Principle of trustworthiness & 4.41 & 0.59 & Good \\
Principle of confidence, & 4.46 & 0.59 & Good \\
Principle of instant response & 4.44 & 0.59 & Good \\
Principle of regard & 4.38 & 0.59 & Good \\
Principle of objectiveness & 4.44 & 0.60 & Good \\
\hline
\end{tabular}

Table 2 shows that the variable of the principle of confidence, $(\bar{X}=4.46)$, had the highest mean. The variables with the second highest mean were the principle of instant response and the principle of objectiveness $(\bar{X}=4.44)$. The lowest mean was the principle of regard $(\bar{X}=4.38)$. All variables are at a "good" level.

7.2 Analytical results of the confirmatory factors of the academic service-learning principles and professions of the Institute of Vocational Education, Bangkok

Table 3: Assumption analysis results of the confirmatory factors of the academic service-learning principles and professions of the Institute of Vocational Education, Bangkok

\begin{tabular}{lccc}
\hline Variables & KMO & $\begin{array}{c}\text { Bartlett's Test of } \\
\text { Sphericity }\end{array}$ & Sig. \\
\hline $\begin{array}{l}\text { The academic service-learning principles and professions of the } \\
\text { Institute of Vocational Education,. Bangkok }\end{array}$ & 0.91 & 1945.42 & 0.00 \\
\hline
\end{tabular}

From Table 3, the assumption analysis results of the confirmatory factors of the academic servicelearning principles and professions of the Institute of Vocational Education, Bangkok, had a KMO > 0.5 , and Bartlett's Test of Sphericity had statistical significance at .05; this means the information is suitable with the confirmatory factor analysis. After it was analyzed with construct validity, it was found that the variables of the academic service-learning principles and professions of the Institute of Vocational Education; Bangkok, had one over Initial Eigenvalues and factors. This means that all questions were factors of the variables of the academic service-learning principles and professions of the Institute of Vocation Education, Bangkok.

Table 4: Correlation values of the variables of principle of trustworthiness, principle of confidence, principle of instant response, principle of regard, and principle of objectiveness

\begin{tabular}{cccccc}
\hline Variables & b1 & b2 & b3 & b4 & b5 \\
\hline b1 & 1.000 & & & & \\
b2 & $.858^{* * *}$ & 1.000 & & & \\
b3 & $.806^{* * *}$ & $.832^{* * *}$ & 1.000 & & \\
b4 & $.774^{* * *}$ & $.833^{* * *}$ & $.836^{* * *}$ & 1.000 & \\
b5 & $.725^{* *}$ & $.806^{* *}$ & $.783^{* *}$ & $.855^{* *}$ & 1.000 \\
\hline
\end{tabular}

$* * p<.01$ 
From Table 4, all variables were related and had statistical significance at .01; the highest related principles were the principle of trustworthiness (b1) and the principle of confidence (b2). Their correlation value was 0.858 . The second highest related principles were the principle of regard (b4) and the principle of objectiveness (b5). Their correlation value was at 0.855 The least were the principle of trustworthiness and the principle of objectiveness. Their correlation was at 0.725 .

Table 5: Analytical results of the confirmatory factors of the academic service-learning principles and professions of the Institute of Vocational Education, Bangkok.

\begin{tabular}{lc}
\hline Visible Variables & Value of Factors \\
\hline Principle of trustworthiness & $0.84^{*}$ \\
Principle of confidence, & $0.92^{*}$ \\
Principle of instant response & $0.90^{*}$ \\
Principle of regard & $0.92^{*}$ \\
Principle of objectiveness & $0.89^{*}$ \\
\hline$p<.05, \chi^{2}=5.26, \mathrm{df}=4, \chi^{2} / \mathrm{df}=1.32, \mathrm{p}$-value $=0.26, \mathrm{GFI}=0.99, \mathrm{AGFI}=0.98, \mathrm{RMSEA}=0.03$
\end{tabular}

Table 5 shows the harmony analytical results of the academic service-learning principles and professions of the Institute of Vocational Education, Bangkok, and the visible information. It was found that the analytical results harmonized with the visible information. The Chi-square value was different from 0 , and had no statistical significance $\left(\chi^{2}=5.26, \mathrm{df}=4, \chi^{2} / \mathrm{df}=1.32, \mathrm{p}\right.$-value $=0.26$ ). The Goodness of - Fit Index (GFI) was at 0.99, the Adjusted Goodness of Fit (AGFI) was at 0.98, and the Root Mean Square Error of Approximation (RMSEA) was at 0.03 . Therefore, it can be concluded that the analytical results of the academic service-learning principles and professions of the Institute of Vocational Education, Bangkok, was harmonized with the visible information, as shown in the Figure 1:

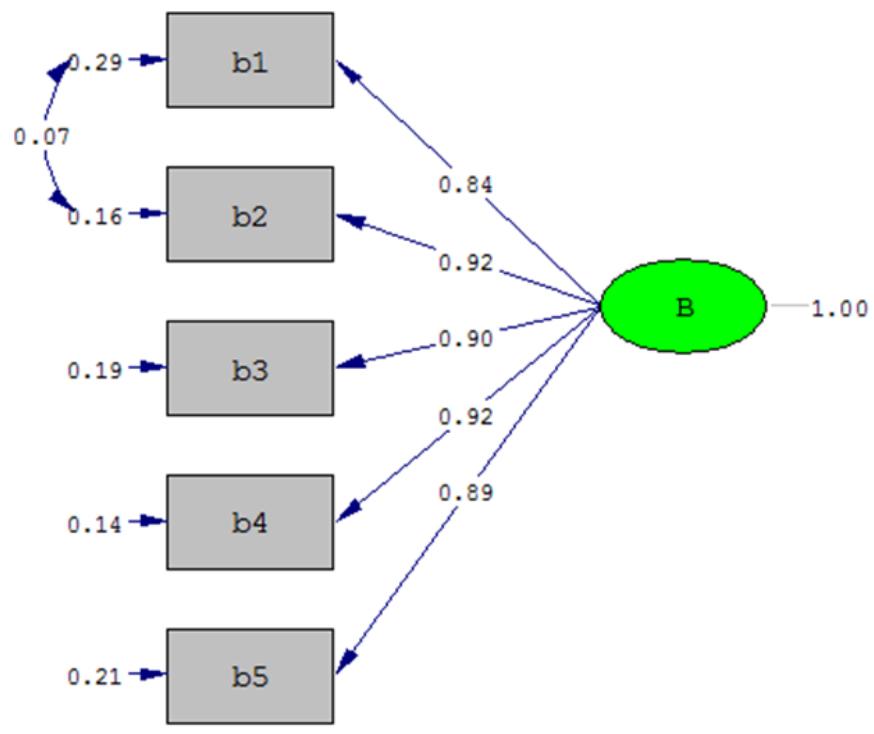

Chi-Square $=5.26$, df $=4, \mathrm{P}$-value $=0.26121, \mathrm{RMSEA}=0.029$

Figure 1. Analytical result of the confirmatory factors of the academic service-learning principles

From Figure1 shows the analytical results of the confirmatory factors of the academic servicelearning principles and professions of the Institute of Vocational Education, Bangkok. There were 
five visible variables; the principles of trustworthiness, confidence, instant response, regard, and objectiveness. Their values was at $0.84,0.92,0.90,0.92$, and 0.89 , respectively; all values had statistical significance at .05

\section{Discussion}

The analytical results of the confirmatory factors of the academic service-learning principles and professions of the Institute of Vocational Education, Bangkok, show that the factor principles of confidence and of regard had the highest value, at 0.92 . This is because instilling confidence and having the best regard towards the service users are the most important principles of service. Service itself means those activities or advantages that a business offers to the customer, in order to satisfy that customer make them pleased with the service. This is consistent with Štefan Chudý (2008) stated that a functional model of competences, which will be veri ed in practice and subsequent are section on the professional preparation of social pedagogues at TBU in Zlin. We shall base upon the knowledge and observations contained in the current professional literature as well as working practices (i.e. praxis). Decision-making competences - on which our attention and activities are focused in this paper, are highly specific competences. e decision-making competence is not understood (by us) from the perspective of technical, economic, or social policies, but rather from the perspective of key competences - which are the load-bearing competences, and at the same time, include within themselves a dimension of other competences and these individual competences intermingle to various degrees as does their content. Ligeti, and Oravecz, (2009), who researched "communication of corporate enterprises in Hungary," and found that all enterprises require profit. However, all enterprises need to be responsible to society. Many enterprises create charitable activities that are suitable with their communication plans, but simultaneously pay less attention towards questions about their reliability. This is agreed with Brown, Bettina Lankard (1998) founded that service learning, like apprenticeship and school-towork, contextualizes student learning. It provides an environment in which students can acquire organizational, team, problem-solving, and other skills, attitudes, and capabilities necessary for future work and learning. This ERIC Digest looks at service learning: what it is and how it supports vocational and career development outcomes. This is consistent with Chaloemkiat et al. (2006), which studied the present condition of the academic service-learning of Chandrakasem Rajabhat University). It was found that universities should instill academic service-learning, in order to deliver necessary education to society, not to gain profit. Also Kiely, Richard (2005) stated that the servicelearning model presented here offers researchers a number of conceptual categories that need more thorough examination in diverse service-learning programs. This study is one of many steps to be taken to address theoretical and empirical gaps in moving the normative vision for serviceleaning toward transformative practice and impact. For the service-learning field to realize such a vision, it is necessary to develop a unified and comprehensive experiential learning theory grounded in, and highlighting dimensions of, learning that is both transform.

\section{Conclusions}

The analytical results of the confirmatory factors of the academic service-learning principles and professions of the Institute of Vocational Education, Bangkok was harmonized with the visible information. In addition, the analysis results showed that there were 5 visible variables; the principles of trustworthiness, confidence, instant response, regard, and objectiveness. Their values were at $0.84,0.92,0.90,0.92$, and 0.89 , respectively; all values had statistical significance at 05 .

\section{Acknowledgements}

I would like to express my sincere thanks to the special expert and others person for suggestions and all their help for my research. 


\section{References}

Berry, Leonard L., Valarie A. Zeithamal, and A. Parasuraman. 1990. "Five Imperatives for Improving Service Quality. "Sloan Management Review. 31. (1990) : 29 - 38.

Brown, Bettina Lankard. 1998. "Service Learning: More than Community Service". Service Learning, General. 126. https://digitalcommons.unomaha.edu/slceslgen/126.

Chalerm Kiatdanakul, et al., 2006. Principles, Guidelines and Models of Academic Services for the Society of Chandrakasem Rajabhat University. Research report. Bangkok: Chandrakasem Rajabhat University.

Hair, J., Blak, W.C., Barbin, B.J., Anderson, R.E., \& Tatham, R.L. 2010. Multivariate Data Analysis. New Jersey: Upper Sandle River, Prentice Hall, p. $94-118$.

Jittinan Nantapaiboon 2008. Service psychology. Bangkok : SE-EDUCATION Public Company Limited.

Kathleen B. Wasserman .Elementary teacher utilisation of service learning as methodology during student teaching placements Issues in Educational Research, 20(1), 2010. Special edition on service learning.

Kiely, Richard. 2005. A Transformative Learning Model for Service-Learning: A Longitudinal Case Study. Michigan Journal of Community service Learning. Volume 12, Fall 2005. http://hdl.handle.net/2027/spo.3239521.0012.101.

Ligeti, G. \& Oravecz, A. CSR 2009. Communication of Corporate Enterprises in Hungary. Journal of Business Ethics. 84 (January 2009): 137-149.

Mesinsi Suvit. 2016. The paper of the Conference of School Administrators in Vocational Education Institutions for the year 2016 from $22^{\text {nd }}$ to $23^{\text {rd }}$ at Deatide Hotel, Bangsaen, Chonburi. Thailand.

Office of the National Economic and Social Development Board.2017. Summary of National Economic and Social Development Plan Eleventh edition. 2012-2016. [Online] Retrieved on 21 May 2019, http://www.Idd.go.th/.

Office of the Vocational Education Commission. 2014. Policy and Strategy for Education Reform in Vocational Education Development [Online] Retrieved on December 15, 2015, from www.vec.go.th.

Pisit Pipatpokakun. 2008. Service to the heart ... everyone come back. Bangkok: Thailand Productivity Institute.

Štefan Chudý. 2008. Development and Creation Determinants of Decision-making Competences in the Preparation of Social (Services) Pedagogues at TBU in Zlin. The New Educational Review .Volume $16 / 2008$. 